\title{
Factors Determining Health Institutional Delivery Among Pregnant Women Living in Agarfa Town of Bale Zone, Oromia, South East Ethiopia
}

\author{
Tomas Benti Tefera ${ }^{1}$, Kemal Ahmed Kuti ${ }^{2}$ \\ ${ }^{1}$ Department of Nursing, Madawalabu University, College of Medicine and Health Sciences, Southeast Ethiopia \\ ${ }^{2}$ Department of Public Health, Madawalabu University, College of Medicine and Health Sciences, Southeast Ethiopia
}

Email address:

thomas_benti@yahoo.com (T. B. Tefera),kemal.ahmed5@gmail.com (K. A. Kuti)

\section{To cite this article:}

Tomas Benti Tefera, Kemal Ahmed Kuti. Factors Determining Health Institutional Delivery Among Pregnant Women Living in Agarfa Town of Bale Zone, Oromia, South East Ethiopia. American Journal of Health Research. Vol. 3, No. 3, 2015, pp. 130-134.

doi: 10.11648/j.ajhr.20150303.13

\begin{abstract}
Background: About 800 women die from pregnancy- or childbirth-related complications around the world every day. In 2013, 289000 women died during and following pregnancy and childbirth. Almost all of these deaths occurred in low-resource settings. According to the latest estimate maternal mortality ratio in Ethiopia was 420/100,000 live births in 2013 which is still high. Severe bleeding, infection, high blood pressure during pregnancy and complication from delivery, accounts for nearly $75 \%$ of these deaths. Even though ANC follows up, Institutional delivery and skilled birth attendance is one of the key and proven interventions to reduce maternal death most deliveries, in Ethiopia, skilled birth attendance and birth in a health facility is very low. So this study aimed to assess Factors determining Health institutional delivery among pregnant women living in Agarfa woreda of Bale Zone, Southeast Ethiopia. Methods: Community based cross sectional study was conducted in Agarfa Town from January -March, 2012 on one hundred fifty six pregnant women in the town. Systematic sampling was used to get the respondents after sampling frame including lists of households having pregnant women was prepared. Data were analyzed using SPSS version 15.0. Binary and multivariable logistic regression analyses were carried out to identify factors associated with institutional delivery service. Statistical significance was considered at $\mathrm{p}<0.05$. Results: The response rate was $98.7 \%(\mathrm{n}=156)$. The proportion of pregnant women who had given birth at health institution were 49(31.4\%), of 118 who had followed ANC for recent pregnancy, only $27(22.9 \%)$ were gave birth at health institution. Factors associated with health institution delivery were the number of pregnancies (three and above) and difficulty labour. However, difficulty labour/prolonged was remained a significant predictor of institutional delivery. Conclusions: Despite the high level of ANC attendance among the pregnant women in the study area, the study has revealed that mothers were not considerably utilizing institutional delivery and skilled birth attendants and majority of them still choose Home delivery. Pregnant women wait till they experience difficult labour to seek health institutional delivery.
\end{abstract}

Keywords: Maternal Health, Child Health, Delivery, Birth Attendants, Pregnant Women, Home Delivery, Health Institution Delivery

\section{Background}

Maternal mortality is unacceptably high. About 800 women die from pregnancy- or childbirth-related complications around the world every day. In 2013, 289000 women died during and following pregnancy and childbirth. Almost all of these deaths occurred in low-resource settings, and most could have been prevented [1].

In sub-Saharan Africa, a number of countries have halved their levels of maternal mortality since 1990. In other regions, including Asia and North Africa, even greater headway has been made. However, between 1990 and 2013, the global maternal mortality ratio declined by only $2.6 \%$ per year. This is far from the annual decline of $5.5 \%$ required to achieve MDG5 [1].

The maternal mortality ratio in developing countries in 2013 is 230 per 100000 live births. In Ethiopia, According to the latest estimate maternal mortality ratio has declined from $676 / 100,000$ live births in 2011 to $420 / 100,000$ live births in 2013. However, still far to achieve the target for 2015 that is 
$267 / 100,000$ live births [1].

Over 30 million women in the developing world suffer from serious diseases and disabilities which include uterine prolapsed, fistula, incontinence, and pain during sexual intercourse as a result of inadequate or inappropriate care during delivery or the first critical hours after birth [2].

The major complications that account for nearly $75 \%$ of all maternal deaths are includes severe bleeding (mostly bleeding after childbirth),infections (usually after childbirth), high blood pressure during pregnancy (pre-eclampsia and eclampsia), complications from delivery and unsafe abortion[3].

Antenatal care from a trained provider is important to monitor the pregnancy and reduce these high morbidity and mortality risks for the mother and child during pregnancy and delivery and It presents an important opportunity for identifying threats to the mother and unborn baby's health, as well as for counseling on nutrition, birth preparedness, delivery care and family planning options after the birth [4].

In Ethiopia, antenatal care coverage, at least one visit and four visits was $42.5 \%$ and $19.1 \%$ respectively [5]. Even though Institutional delivery service utilization skilled birth attendance is one of the keys and proven interventions to reduce maternal death most deliveries in developing countries occur at home without skilled birth attendants [6] still a birth attended by skilled provider was about 10\% [7] and Births in a health facility was about $9.9 \%$ in Ethiopia [8].

The recent Ethiopian Demographic and Health Survey also revealed that $8 \%$ of births were delivered in a health facility in Oromia region respectively [8]. This indicates that still the Magnitudes of Home delivery in Ethiopia are very high. So this study aimed to assess Factors determining Health institutional delivery among pregnant women living in Agarfa woreda of Bale Zone, Southeast Ethiopia.

\section{Methods}

\subsection{Study Setting and Sample}

Community based cross sectional study was conducted in Agarfa Town from January -March, 2012 on pregnant women in the town. Agarfa town is located in the Bale Zone of Oromia region and 465KMs Southeast of Ethiopia.

The Sample size was determined using single population proportion formula taking the prevalence of institutional delivery service at National level (10\%) (EDHS,2011) with 95\% confidence level, $5 \%$ margin of error and $15 \%$ for non response was added, the final sample size was 158 women.

Systematic Random sampling was used to get the respondents after sampling frame including lists of households having pregnant women was prepared. In Case of more than one eligible woman in selected household, lottery method was used to select one of the eligible women.

\subsection{Data Collection Tool and Procedures}

Data were collected using structured, interviewer administered Afaan Oromo (local language) Version questionnaire. Socio-demographic, history of abortion and stillbirth, history of difficulty labour(including history of bleeding, prolonged labour), ANC service Utilization for recent pregnancy, Number of ANC visit, Health education/advice on places of delivery at ANC visit for recent pregnancy, whether the recent pregnancy was planned or not, Place of delivery of recent pregnancy, and numbers of pregnancy were collected. Home delivery was considered when a mother reported birth at home (other than health institution) to her recent pregnancy. Data were collected through face to face interview. Data collectors and supervisors were trained for two days in the data collection methods of the study. To ensure data quality, pre-testing of the research tool and translation of the tool for local language (Afaan Oromo) were done. The filled data were checked for completeness on a daily basis and feedback was given to data collectors in the next morning.

\subsection{Data Analysis}

Data were checked for completeness and inconsistencies, coded, entered, cleaned and analyzed using SPSS version 15.0. Descriptive statistics were computed to determine proportions. Binary and multivariable logistic regression analyses were carried out to identify factors associated with institutional delivery service. The strength of statistical association was assessed by odds ratios (OR) with $95 \%$ confidence intervals. Statistical significance was considered at $\mathrm{p}<0.05$.

\subsection{Ethical Clearance}

Letter of ethical approval was received from Research and community coordinator of College of Medicne and health sciences, Madawalabu University. The intention of the study, potential risk and benefits and rights of participants were explained. Verbal consent was obtained from the participants. The participants were assured about the confidentiality of the information they provided.

\section{Results}

\subsection{Socio Demographic Characteristics of Study Subjects}

The overall response rate was $98.7 \%$. Of all study subjects included in the study about 88 (56.4\%) were Muslim in religion and About 38 (24.4\%) of mothers were illiterate. Among the respondents, 26 (16.7\%) had illiterate husband. Concerning their occupational status about $75(48.1 \%)$ of the women were house wife.

Of the total study subjects, $107(68.8 \%)$ were gave birth at home for their recent delivery while $49(31.4 \%)$ were gave birth at health institution. The major reason for home delivery was Easy labour and Unexpected labour86 (80.4\%), followed by cultural influence $9(8.4 \%)$. Of 118 , who visited antenatal care for their recent pregnancy, 91(77.1\%) of them gave delivery at home.

Of total study subjects, $10(6.4 \%)$ of study subjects were had history of abortion and $7(4.5 \%)$ had history of still birth. Regarding their recent Delivery, about 130(83.3\%) was 
reported that the pregnancy was planned. They were asked about history of difficulty/prolonged labour for their recent pregnancy, 19(16.1\%) had experienced difficulty labour while the other not.

\subsection{Awareness about ANC Services and its Utilization}

All women were heard about Antenatal care services. The major source of information were Health institution and Mass Media, 74(51.0\%) 62(42.7\%) respectively. One hundred Eighteen were visited health institution for their recent pregnancy. Regarding the frequency of visit about $43(36.4 \%)$ were visited at least once while about $12(10.2 \%)$ were visited four and above. During their visit about $80(67.8 \%)$ were given advice on place of delivery while the rest $n$

\section{Discussion}

In Ethiopia, the levels of maternal mortality are decreased to $420 / 100,000 \mathrm{LB}$ in 2013 [1]. It was well known that majority of maternal deaths is due to direct obstetrical complications which could be prevented by Antenatalcare follow up and Health Institution Delivery by skilled Health Professionals. However still a number of women still prefer to deliver at home than to deliver in the health facilities[8].

However, this study found that $68.6 \%$ of the pregnant women had their last delivery at home. Finding from rural area of Zambia revealed that home delivery was about $57 \%$, In Ilesha, Nigeria, about $44.2 \%$ of delivery was non-institutional delivery and Russia village of Jos North, Nigeria also showed that about 56 (40\%) had their last delivery a home. Despite the figure difference these findings are consistent with our finding agreeing with the fact that a number of women in the developing countries prefer to deliver at home instead of the hospital [10,11].

Despite the high number of pregnant women who attended ANC in this study, about $77.1 \%$ were chose home delivery for their recent pregnancy. This finding is in line with finding in Zaria, Nigeria which also found that adequate ANC attendance during pregnancy did not significantly influence hospital delivery[12].

Despite advances in the health system, rates of skilled attendance at birth remain very low at $10 \%$. The five known direct causes of maternal mortality were postpartum hemorrhage, sepsis, eclampsia, obstructed labour, and unsafe abortion. Several reasons are cited for the low uptake of maternal health services, particularly in facilities, including distance, lack of transportation, cost, poor quality of care, and women's lack of decision-making power [13].

This study also found that the reason for home delivery were easy and unexpected labour, no transportation, poor service delivery and cultural influences. whatsoever, All women need access to skilled care during childbirth, and care and support in the weeks after childbirth[14]. This is only achieved if all when pregnant women gave birth at health institution and no way home delivery.

Despite less institutional delivery, Ethiopia is comprehensively working on escalating institutional delivery by focusing on making pregnancy safer by providing free maternal and child health services to its population, improving health infrastructure throughout the country, and enhancing the training of its primary health care workforce[15].

Some studies in developing countries have shown that the decision to deliver at home is related to socio-demographic and economic factors such as income, educational status and marital status [16,17]. However, in this particular study, Experiencing difficulty labour and the number of pregnancies (three and above) were a significant predictor of institutional delivery on binary logistic regression. However, experience of difficulty labour was remain a significant predictor of institution delivery on multivariable logistic regression and those women who had experienced difficulty labour were more likely to give birth at the health institution compared to those who hadn't. This finding is consistent with finding from Samre Saharti District, Tigray, Ethiopia, which revealed that women who had a history of obstructed labor were more likely to select Health facility for delivery service than women who had not that experience [18].

\section{Conclusions and Recommendations}

In general, Despite the high level of ANC attendance among the pregnant women in the study area, the study has revealed that mothers were not considerably utilizing institutional delivery and skilled birth attendants and majority of them still choose Home delivery. Pregnant women wait till they experience difficult labour to seek health institutional delivery. So, Emphasis should also be given for capacity building for skilled birth attendants and HEWs currently working in the study area to effectively work in increasing institutional delivery by collaborating with different sectors in the town through the provision of regular health education on the danger of Home delivering as a way of increasing the institution delivery and reducing maternal mortality in the country.

Table 1. Distribution of socio-demographic characteristics of the study participants in Agarfa Town, Southeast Ethiopia, January - March, 2012 $(n=156)$.

\begin{tabular}{|c|c|c|c|c|}
\hline Variables & Categories & & Frequency & Percentage \\
\hline \multirow[t]{3}{*}{ Age } & $15-24$ & & 68 & 43.6 \\
\hline & $25-34$ & & 72 & 46.2 \\
\hline & $35-49$ & & 16 & 10.3 \\
\hline \multirow{3}{*}{ Religion } & Muslim & & 88 & 56.4 \\
\hline & Christian & & 68 & 43.6 \\
\hline & Oromo & & 121 & 77.6 \\
\hline \multirow[t]{3}{*}{ Ethnicity } & Amhara & & 31 & 19.2 \\
\hline & Tigre & & 5 & 1.9 \\
\hline & Illiterate & & 26 & 16.7 \\
\hline \multirow{3}{*}{$\begin{array}{l}\text { Husband } \\
\text { Education }\end{array}$} & Primary(1-8) & & 68 & 43.6 \\
\hline & Secondary $(9-12)$ & & 31 & 19.9 \\
\hline & $\begin{array}{l}\text { Tertiary(College \& } \\
\text { Above }\end{array}$ & & 31 & 19.9 \\
\hline \multirow{4}{*}{$\begin{array}{l}\text { Women's } \\
\text { Education }\end{array}$} & Illiterate & & 38 & 24.4 \\
\hline & Primary(1-8) & & 76 & 48.7 \\
\hline & Secondary(9-12) & & 30 & 19.2 \\
\hline & $\begin{array}{l}\text { Tertiary(College } \\
\text { Above) }\end{array}$ & $\&$ & 12 & 7.7 \\
\hline
\end{tabular}




\begin{tabular}{llll}
\hline Variables & Categories & Frequency & Percentage \\
\hline & Farmers & 37 & 23.7 \\
& Housewife & 75 & 48.1 \\
Women & Merchant & 17 & 10.9 \\
Occupation & Governmental & 15 & 9.6 \\
& employee & 12 & 7.7 \\
\hline
\end{tabular}

\begin{tabular}{lll}
\hline Variables & Number & Percentages \\
\hline No & 149 & 95.5 \\
Pregnancy Planned & & \\
Yes & 130 & 83.3 \\
No & 26 & 16.7 \\
History of difficulty labour & & \\
Yes & 19 & 16.1 \\
No & 99 & 83.9 \\
\hline
\end{tabular}

Table 2. Distribution of study subjects by place of Recent delivery of their last child at Agarfa Town, Southeast Ethiopia January - March, 2012(n=156).

Table 4. Distribution of study subjects according to their awareness about

\begin{tabular}{lll}
\hline Variables & Number & Percentage \\
\hline Place of the recent birth & 107 & 68.6 \\
Home & 49 & 31.4 \\
Health institution* & & \\
Reason for home delivery & & 80.4 \\
Easy and Unexpected labour & 86 & 7.5 \\
No transportation & 8 & 1.8 \\
Poor service Delivery & 2 & 8.4 \\
Cultural influence & 9 & 1.8 \\
HEW is always available & 2 & \\
\hline
\end{tabular}

*Health institution includes birth at Private clinic, Health post/centers and Hospital

Table 3. Distribution of Obstetric factors among study subjects at Agarfa Town, Southeast Ethiopia, January - March, 2012(n=156).

\begin{tabular}{|c|c|c|}
\hline Variables & Number & Percentages \\
\hline \multicolumn{3}{|l|}{ Number of pregnancy } \\
\hline $1-4$ & 134 & 85.9 \\
\hline $5 \&$ Above & 22 & 14.1 \\
\hline \multicolumn{3}{|l|}{ Child ever born } \\
\hline One & 51 & 32.5 \\
\hline $2-5$ & 63 & 40.4 \\
\hline$>5$ & 4 & 2.6 \\
\hline \multicolumn{3}{|l|}{ History of abortion } \\
\hline Yes & 10 & 6.4 \\
\hline No & 146 & 93.6 \\
\hline \multicolumn{3}{|l|}{ History of still birth } \\
\hline Yes & 7 & 4.5 \\
\hline
\end{tabular}

ANC and its utilization at Agarfa Town, Southeast Ethiopia, January - March, 2012(n=156).

\begin{tabular}{l|ll}
\hline Variables & Number & Percentage \\
\hline Heard About ANC & 156 & 100 \\
Yes & 0 & 0.0 \\
\hline $\begin{array}{l}\text { No } \\
\text { Source of information }\end{array}$ & 74 & 47.4 \\
$\begin{array}{l}\text { Health institution } \\
\text { mass media }\end{array}$ & 73 & 46.8 \\
$\begin{array}{l}\text { Relatives/friends } \\
\text { Visit for recent pregnancy }\end{array}$ & 9 & 5.8 \\
Yes & 118 & 75.6 \\
No & 38 & 24.4 \\
Frequency of visit for recent pregnancy & & \\
At least once & 43 & 36.4 \\
2-3 times & 63 & 53.4 \\
4 and above & 12 & 10.2 \\
\hline Advice on place of delivery at ANC Visits on & & \\
recent pregnancy & & \\
Yes & 80 & 67.8 \\
\hline No & 38 & 32.8 \\
\hline
\end{tabular}

Table 5. Predictors of Institutional delivery among study subjects at Agarfa Town, Southeast Ethiopia, January - March, 2012(n=156).

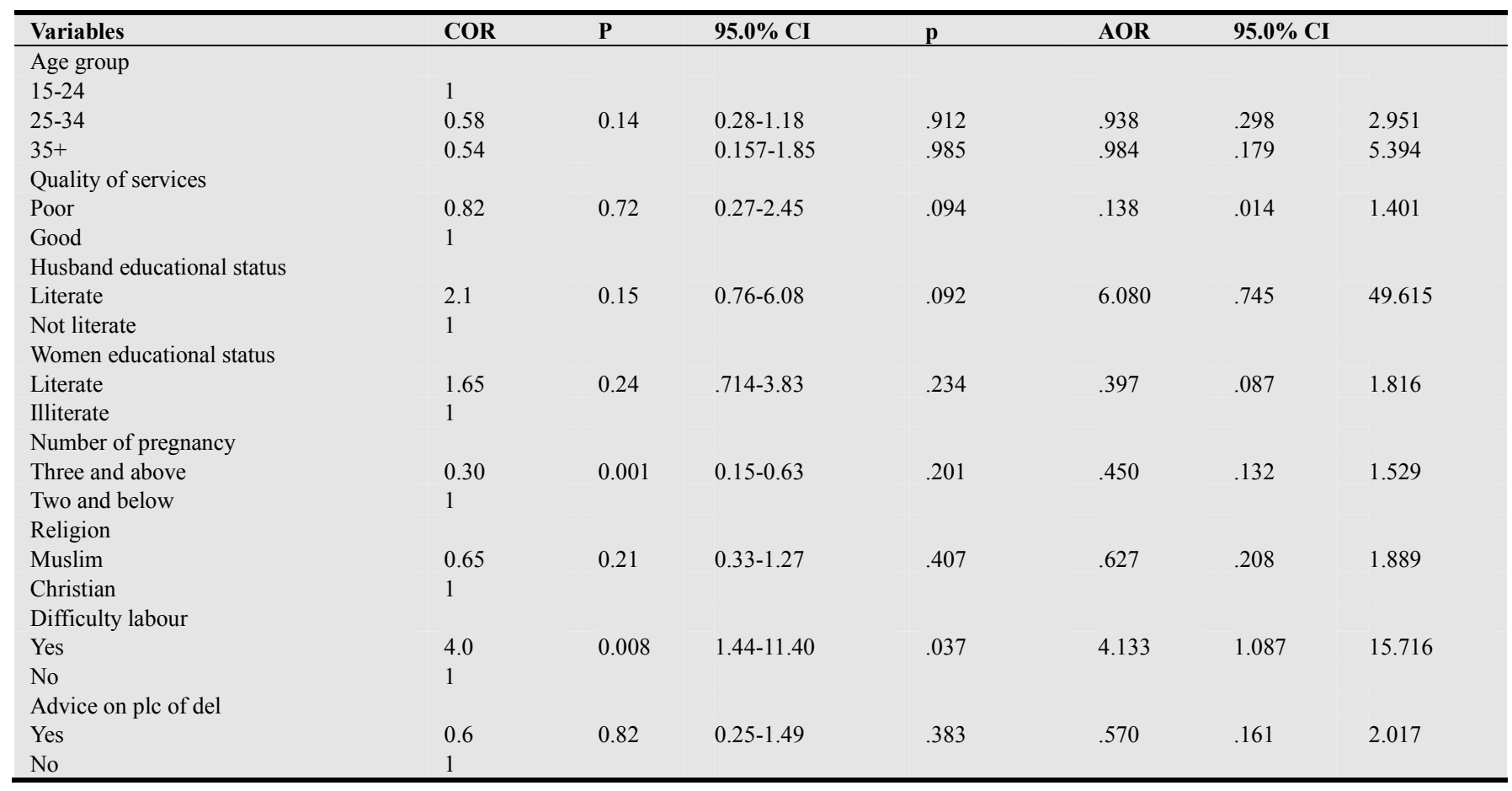




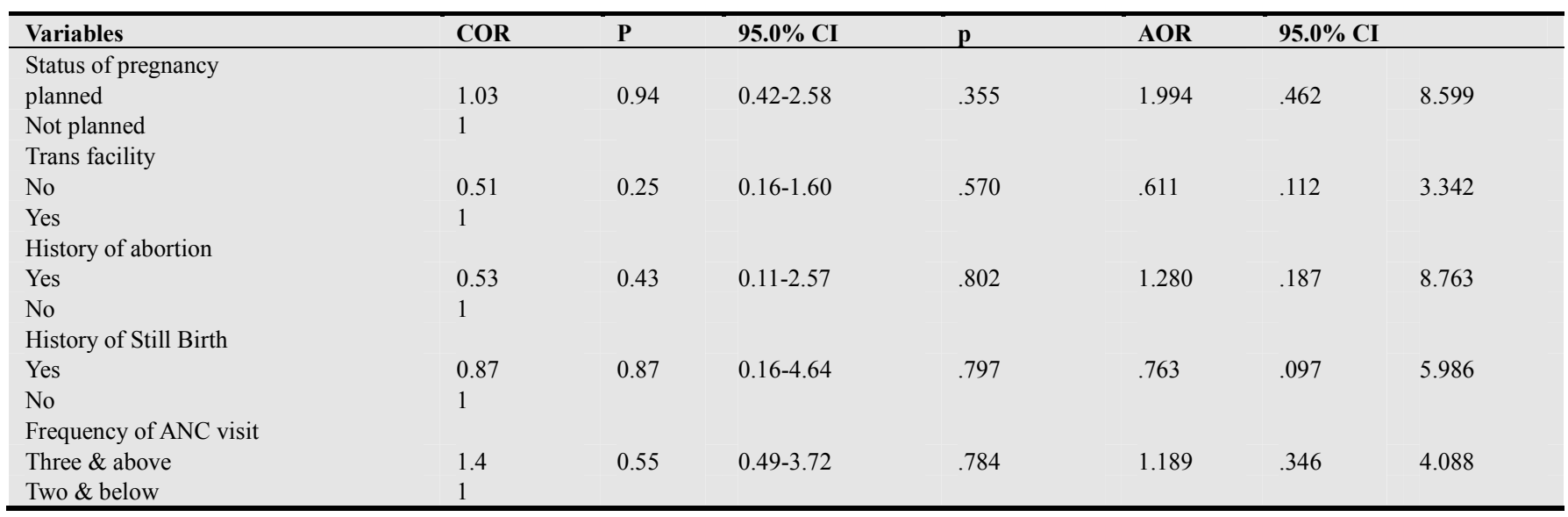

$\mathrm{COR}=$ Crude Odd ratio, $\mathrm{P}=\mathrm{p}$ value, $\mathrm{CI}=$ confidence interval, $\mathrm{AOR}=$ Adjusted Odd Ratio

\section{Authors' Contributions}

KA and TB conceived the idea, designed the study; TB involved in statistical analysis and drafted the manuscript. All authors participated in the write up; read and approved the final manuscript.

\section{Acknowledgments}

We would like to thank Madawalabu University, research and community Service coordinator of CMHS. We also thank Agarfa town Health administrators for facilitating the study and individuals who have participated in the study.

\section{References}

[1] United Nations Development Programme. Trends in Maternal Mortality: 1990 to 2013. Available from http://unfpa.org/webdav/site/global/shared/documents/ publications/2014/9789241507226_eng.pdf.

[2] WHO. Fact sheets Maternal Mortality: 2005

[3] Say L et al. Global Causes of Maternal Death: A WHO Systematic Analysis. Lancet. 2014.

[4] WHO. What is the effectiveness of antenatal care? (Supplement). Copenhagen, WHO Regional Office for Europe, Health Evidence Network report,2005

[5] UNICEF. Ethiopia Statistics; 2013. Available from http://www.unicef.org/infobycountry/ethiopia_statistics.html\# 119

[6] WHO, UNICEF, UNFPA and World Bank. Trends in Maternal Mortality: 1990 to 2010. Geneva 27, Switzerland: World Health Organization; 2012.

[7] World Bank. Ethiopia | Data. World Bank; 2012
[8] Central Statistical Agency [Ethiopia] and ICF International. 2012. Ethiopia Demographic and Health Survey 2011. Addis Ababa, Ethiopia and Calverton, Maryland, USA: Central Statistical Agency and ICF International

[9] United Nations Development Programme. Trends in Maternal Mortality: 1990 to 2013. Available from http://unfpa.org/webdav/site/global/shared/documents/ publications/2014/9789241507226_eng.pdf.

[10] Hazemba AN, Siziya S. Choice of place for childbirth: prevalence and correlates of utilization of health facilities in Chongwe district. Zambia. Med J Zambia 2008; 35:53-57.

[11] Cotter K, Hawken M, Temmerman M: Low use of skilled attendants' delivery services in rural Kenya. $J$ Health Popul Nutri 2006; 24:467-71.

[12] Idris S.H, Gwarzo U.M.D, Shehu A.U: Determinants of place of delivery among women in a semi-urban settlement in Zaria, Northern Nigeria. Ann Afr Med 2006; 5:68-72.

[13] Darmstadt GL, Lee AC, Cousens S, et al. 60 Million non-facility births: who can deliver in community settings to reduce intrapartum-related deaths? International Journal of Gynecology and Obstetrics 2009; 107(S1): S89-112.

[14] WHO. Maternal Mortality. Fact sheet, 2012.

[15] Ethiopia Ministry of Health. Health Sector Development Programme-IV. 2011. Available from http://bit.ly/RmGWvL

[16] Katung PY: Socio-economic factors responsible for poor utilization of primary health care services in a rural community in Nigeria. Nig J Med 2001; 10:20-59.

[17] Satoko Y, Sophal O, Susumu W: Determinants of skilled birth attendance in rural Cambodia. Trop Med Int Health 2006; $2: 238-251$.

[18] Tsegay et al.: Determinants of antenatal and delivery care utilization in Tigray region, Ethiopia: a cross-sectional study. International Journal for Equity in Health 2013; 12:30. 